\title{
Role of the Liver in Regulation of Ketone Body Production during Sepsis
}

\author{
Robert W. Wannemacher, Jr., Judith G. Pace, Francis A. Beall, Richard E. \\ Dinterman, Vance J. Petrella, and Harold A. Neufeld, U. S. Army Medical \\ Research Institute of Infectious Diseases, Fort Detrick, Frederick, Maryland 21701
}

A B S T RAC T During caloric deprivation, the septic host may fail to develop ketonemia as an adaptation to starvation. Because the plasma ketone body concentration is a function of the ratio of hepatic production and peripheral usage, a pneumococcal sepsis model was used in rats to measure the complex metabolic events that could account for this failure, including the effects of infection on lipolysis and esterification in adipose tissue, fatty acid transport in plasma and the rates of hepatic ketogenesis and whole body oxidation of ketones. Some of the studies were repeated with tularemia as the model infection. From these studies, it was concluded that during pneumococcal sepsis, the failure of rats to become ketonemic during caloric deprivation was the result of reduced ketogenic capacity of the liver and a possibly decreased hepatic supply of fatty acids. The latter appeared to be a secondary consequence of a severe reduction in circulating plasma albumin, the major transport protein for fatty acids, with no effect on the degree of saturation of the albumin with free fatty acids. Also, the infection had no significant effect on the rate of lipolysis or release of fatty acids from adipose tissue. Ketone body usage (oxidation) was either unaffected or reduced during pneumococcal sepsis in rats. Thus, a reduced rate of ketone production in the infected host was primarily responsible for the failure to develop starvation ketonemia under these conditions. The liver of the

In conducting the research described in this report, the investigators adhered to the "Guide for the Care and Use of Laboratory Animals," as promulgated by the Committee on Care and Use of Laboratory Animals of the Institute of Laboratory Animal Resources, National Research Council. The facilities are fully accredited by the American Association for Accreditation of Laboratory Animal Care.

The views of the authors do not purport to reflect the positions of the Department of the Army or the Department of Defense.

Dr. Petrella's present address is Gillette Medical Evaluation Laboratory, Rockville, Md. 20850.

Received for publication 13 December 1978 and in revised form 13 August 1.979. infected rat host appears to shuttle the fatty acids away from $\beta$-oxidation and ketogenesis and toward triglyceride production, with resulting hepatocellular fatty metamorphosis.

\section{INTRODUCTION}

During acute or prolonged starvation, the body increases its circulating plasma concentrations of ketones, and these are used as a source of energy by tissues such as skeletal muscle and eventually brain (1). This ketonemic adaptation to starvation reduces the need for energy derived from glucose calories, which in turn spares body protein by decreasing the rate of amino acid usage for glucose synthesis. However, there is a general failure of ketonemic adaptation to occur during caloric deprivation associated with severe sepsis in man, monkey, or rodent (2-6). Because of the lack of alternative fuels during severe sepsis, skeletal muscle breaks down protein and increases the usage of amino acids, especially the branched-chain ones, as a source of energy (7). This results in an increased production and release from skeletal muscle of alanine and glutamine, the major substrates used by liver and kidney for gluconeogenesis, ureagenesis and ammoniagenesis. Thus, the failure of the severely septic host to develop starvation ketonemia can explain, in part, the marked increases in urea and ammonia nitrogen excretion and elevated rates of $\mathrm{O}_{2}$ consumption associated with the catabolic aspect of this disease $(7,8)$.

The rate of ketone body formation is a function of both the influx of free fatty acids from peripheral fat deposits to the liver and the extent of hepatic ketogenesis (9-13). In turn, the blood concentration of ketone bodies (acetoacetate and $\beta$-hydroxybutyrate) is a function of both the rate of hepatic production and peripheral usage $(14,15)$. Mechanisms responsible for a failure of starvation ketonemia to develop in the septic host have not been completely determined. Plasma free fatty acid concentrations have been reported to be variably increased or decreased during 
a number of gram-negative or gram-positive bacterial infections and viral illnesses in man and experimental animals $(8,16)$. When rats were made septic by cecal ligation and subjected to a 2-d fast period, plasma free fatty acid concentrations were decreased and fat mobilization appeared to be reduced as compared to measurements made in fasted control rats (5). In contrast, in preliminary studies on perfused livers of infected rats, ketone body production was decreased from oleic acid but not from octanoic acid (17). The present in vivo and in vitro studies were initiated to help elucidate the mechanisms by which sepsis is able to prevent the ketonemic adaptation to starvation during caloric deprivation in rats. A rat-virulent, gram-positive coccus, Streptococcus pneumoniae, was employed to study the effects of sepsis on lipolysis and esterification in adipose tissue, fatty acid transport, hepatic ketogenesis and the rate of oxidation of ketone bodies. Some of the studies were repeated during infection with an obligate intracellular bacterium, Francisella tularensis.

\section{METHODS}

Animals. Male, Fisher-Dunning rats, F-344/Mai J (Microbiological Associates, Walkersville, Md.), weighing 175-200 g were used in these studies. Rats were maintained on a commercial diet (Wayne Lab-Blox, Allied Mills, Inc., Chicago, IIl.) and water ad lib. for 7-10 d before experimental use. The environmental temperature was maintained at $76-78^{\circ} \mathrm{F}$ and a 12 -h light-dark cycle was employed. At $0800 \mathrm{~h}$ on the $1 \mathrm{~d}$ of each study, food was removed from the rats, and they were then injected subcutaneously with $10^{4}$ virulent or heat-killed S. pneumoniae, type 1, strain A5. Other rats were injected intraperitoneally with $10^{6}$ live or heat-killed vaccine strain (LVS) ${ }^{1} F$. tularensis organisms. Rats receiving heatkilled organisms served as controls for each study. Details concerning preparation of the bacterial inocula and the clinical manifestation of the infections have been published elsewhere $(18,19)$. In most studies, samples were obtained from fed or fasted rats 24 or $48 \mathrm{~h}$ after inoculation with either heat-killed or virulent organisms.

In vitro rates of lipolysis and esterification in epididymal fat pads. The fat pads were quickly removed, weighed and used to measure in vitro rates of production and release of glycerol and free fatty acids (FFA), as well as FFA esterification, by the procedure of Vaughan (20). One fat pad from each rat was used to determine initial concentration of FFA and glycerol, whereas the contralateral fat pad was incubated at $37^{\circ} \mathrm{C}$ for $1 \mathrm{~h}$ in Krebs bicarbonate media that contained 3\% fatty acid-poor bovine albumin (CalbiochemBehring Corp., American Hoechst Corp., San Diego, Calif.). At the end of the incubation period concentration of glycerol (21) and of FFA (22) in both tissue and media were determined by automated techniques.

In vivo rates of oxidation of prelabeled body fat. Rats were injected intragastrically with $1 \mathrm{ml} / 100 \mathrm{~g}$ body wt of a solution that contained $6 \mu \mathrm{Ci} / \mathrm{ml}$ of $\left[\right.$ carboxyl $\left.-{ }^{14} \mathrm{C}\right]$ tripalmitin (New England Nuclear, Boston, Mass.). 2 h later, each rat was injected intragastrically with $1 \mathrm{ml} / 100 \mathrm{~g}$ body wt of a $33 \%$

${ }^{1}$ Abbreviations used in this paper: FFA, free fatty acid; LVS, live or heat-killed vaccine strain. dextrose solution. For the next $7 \mathrm{~d}$, rats were maintained on a $18 \%$ casein diet that supplied $40 \%$ of the calories from fat (23). At the end of $7 \mathrm{~d}$, six rats were killed by cervical dislocation, immediately frozen in liquid nitrogen, and the whole rat was pulverized in a precooled mortar and pestle. The lipid from $1 \mathrm{~g}$ of resulting powder was extracted by the procedure of McGarry and Foster (13) and analyzed for ${ }^{14} \mathrm{C}$ and for lipid content. Another sample of the resulting powder was dissolved in $2 \mathrm{~N} \mathrm{KOH}$ and analyzed for ${ }^{14} \mathrm{C}$ content.

Another group of 12 rats, which had been maintained for $7 \mathrm{~d}$ after their oral dose of labeled tripalmitin, were placed in individual, closed-circuit, metabolic cages that allowed for complete collection of urine, feces, and expired $\mathrm{CO}_{2}(24)$. The rats were allowed access to food during the lst $\mathrm{d}$. On day 1 after being placed in the metabolic cages, food was removed; six rats were injected subcutaneously with virulent $S$. pneumoniae and six with heat-killed organisms. Complete expired $\mathrm{CO}_{2}$, urine, and feces collections were continued for the next $2 \mathrm{~d}$ and all samples were analyzed for ${ }^{14} \mathrm{C}$ content. Rats were then killed by cervical dislocation, and analyzed for lipid and ${ }^{14} \mathrm{C}$ content, as described before. These data were used to calculate the daily rate of ${ }^{14} \mathrm{CO}_{2}$ production and percentage of loss of radioactivity in total body lipid.

Measurement of plasma albumin and molar fatty acid: albumin ratio. Plasma albumin concentrations were determined by automated immunoprecipitin techniques (25) employing rabbit anti-rat albumin and rat albumin standard (N. L. Cappel Laboratories, Inc., Cochranville, Pa.). Another standard of plasma was analyzed for FFA content by automated procedures (22). The molar concentration of albumin was calculated by assuming that a gram of albumin was equivalent to $14.9 \mu \mathrm{mol}$.

Measurement of hepatic ketogenesis and fatty acid metabolism in vivo and in vitro. Liver perfusions were performed using a modification of the apparatus of Miller (26) as described (27). The perfusion medium consisted of $70 \mathrm{ml}$ Krebs-Ringer bicarbonate buffer ( $\mathrm{pH} \mathrm{7.4),30} \mathrm{ml} \mathrm{of} \mathrm{washed}$ sheep erythrocytes, $3 \mathrm{~g}$ of fatty acid-poor, bovine serum albumin (Calbiochem-Behring Corp.), and $500 \mathrm{U}$ of heparin. The atmosphere in the closed perfusion system consisted of $95 \%$ of $\mathrm{O}_{2}$ and $5 \% \mathrm{CO}_{2}$. Perfusion of the liver was maintained at $\sim 1 \mathrm{ml} / \mathrm{min}$ per $\mathrm{g}$; the perfusate was recycled. At the end of a $60-\mathrm{min}$ equilibration period, $2.5 \mathrm{ml}$ of a $20-\mathrm{mM}$ solution of either oleic or octanoic acid-albumin complex, which contained $1 \mu \mathrm{Ci} / \mathrm{ml}$ of corresponding $\left[1-{ }^{14} \mathrm{C}\right]$ oleic acid or $\left[1-{ }^{14} \mathrm{C}\right]$ octanoic acid (New England Nuclear) was injected into the perfusion media. After the initial pulse dose, labeled fatty acid solution was infused at the rate of $6 \mathrm{ml} / \mathrm{h}$. The infusion rate was maintained constant by use of a syringe-driven constant infusion pump (Razel Scientific Instruments, Inc., Stamford, Conn.) and $\mathrm{CO}_{2}$ was collected in an absorbent scintillation mixture $(24,28)$. A 3-ml sample of the perfusate was removed at $0,15,30,45$, and $60 \mathrm{~min}$ and analyzed for FFA (22), $\beta$-hydroxybutyrate (29), and acetoacetate (15). The rate of ketogenesis was calculated from the slope of the plot of total ketones in the media vs. time. At the end of the 1-h infusion, the liver was removed, frozen in liquid nitrogen, weighed, and stored at $-20^{\circ} \mathrm{C}$. The pulverized, frozen liver was analyzed for total lipid concentration and radioactivity $(13,28)$. A sample of the $\mathrm{CO}_{2}$ absorbent-scintillation fluid was analyzed for ${ }^{14} \mathrm{C}$ content $(18)$. A sample of the perfusate was saved for the determination of radioactivity in the ketone bodies by the procedure of McGarry and Foster $(13,28)$.

Measurement of hepatic carnitine and derivatives, malonylCoA and rate of ketogenesis by isolated mitochondria. Livers were removed and analyzed for free carnitine, acid-soluble acylcarnitines and acid-insoluble acylcarnitines according to the method of Pace et al. (30). Malonyl-CoA was determined 
by both the procedures of McGarry et al. (31) and Guynn et al. (32).

Mitochondria were prepared from total liver as described $(33,34)$. Oxygen consumption during the oxidation of oleic acid was monitored using a Clark-type oxygen electrode. The reaction mixture contained in a final volume of $3.0 \mathrm{ml}$ potassium Krebs-Henseleit bicarbonate buffer, $\mathrm{pH} 7.4$; sodium oleate, $0.1 \mathrm{mM}$, bound to $0.8 \%$ albumin (molar ratio fatty acid:albumin = 0.95); ATP, $4 \mathrm{mM}$; L-carnitine, $0.1 \mathrm{mM}$; CoASH, $0.05 \mathrm{mM}$, and 3-5 mg mitochondrial protein. These conditions yielded oxidation rates that were maximal and linear for $12 \mathrm{~min}$, at which time the contents of the chamber were transferred to tubes that contained $0.3 \mathrm{ml}$ of $70 \% \mathrm{HClO}_{4}$. The extract was neutralized and assayed for acetoacetate (15) and $\beta$-hydroxybutyrate (26).

Measurement of in vivo rates of ${ }^{14} \mathrm{CO}_{2}$ production and oxidation of $\beta$-hydroxybutyrate and acetoacetate. Rats were injected via the penile vein with either $1 \mu \mathrm{Ci}$ of $\beta-\left[3-{ }^{14} \mathrm{C}\right]-$ hydroxybutyrate (New England Nuclear) or [3-14 C]acetoacetate (New England Nuclear) per $100 \mathrm{~g}$ body wt. Immediately after the administration of the labeled ketone, rats were placed in individual closed-circuit metabolic cages (24). A 5-ml aliquot of the $\mathrm{CO}_{2}$-absorbent scintillation mixture was collected at $0,30,60,120,180$, and $240 \mathrm{~min}$ and analyzed for ${ }^{14} \mathrm{C}$ activity and $\mathrm{CO}_{2}$ content. At the end of the experiment rats were removed from metabolic cages, anesthetized, and bled. Plasma was promptly separated and analyzed for $\beta$-hydroxybutyrate and acetoacetate concentrations $(15,26)$ and radioactivity $(13,29)$.

Statistical analysis. For sequential analysis within a group, data were analyzed by paired one-way analysis of variance. Intergroup comparisons were made by one-way analysis of variance. A $P$ value of $<0.01$ was considered significant under the null hypothesis.

\section{RESULTS}

By $24 \mathrm{~h}$ after inoculation of $S$. pneumoniae or LVS strain of $F$. tularensis, rats were characterized by an elevation of body temperature and other clinical indicators from the acute-phase of the infectious illness. In contrast, by $48 \mathrm{~h}$ after initiating each kind of infection, the rats had a decrease in body temperature, appeared morbid, and died within the next $10 \mathrm{~h}$. There- fore, they were considered to be in the agonal stage of the infection. Fasted rats given heat-killed organisms did not develop a fever and served as fasted controls for each infected group.

In vitro and in vivo effects of infection on rates of lipolysis and fatty acid esterification and transport. The weight of epididymal fat pads progressively decreased during fasting but no significant difference was observed between fat pads of rats inoculated with live or heat-killed S. pneumoniae (Table I). Both glycerol and FFA production was increased during the in vitro incubation of fat pads from fasted rats as compared to fed controls. However, no significant effect of $S$. pneumoniae infection was observed in these studies as compared to fasted controls (Table I). The calculated rate of fatty acid esterification was increased at 24 and $48 \mathrm{~h}$ in fasted rats and was slightly, but not significantly, slower in the fasted-infection group (Table I). The percentage of esterification of the fatty acids, produced as a result of lipolysis of triglycerides, was significantly less in fasted rats compared to fed controls and was not altered from fasting values in the presence of a pneumococcal infection.

When rats were given an oral dose of $\left[{ }^{14} \mathrm{C}\right]$ tripalmitin, followed in $1 \mathrm{~h}$ with a glucose load, $\sim 85-90 \%$ of the label was associated with total body lipids $7 \mathrm{~d}$ later. When fed a purified diet (23), they lost $6.8 \%$ of the label per day in expired $\mathrm{CO}_{2}$ (Table II). During fasting, the rate of loss increased to 9.3 and $15 \%$, respectively at 24 and $48 \mathrm{~h}$. Pneumococcal sepsis imposed upon fasting did not alter the rate of loss of label in the expired $\mathrm{CO}_{2}$ when compared to fasted controls.

Both plasma albumin and FFA concentration were progressively decreased in the fasted pneumococciinfected rats as compared to fasted controls (Table III). Maximum depression in plasma albumin and FFA concentrations were observed in the 48-h infected rats. The molar fatty acid:albumin ratio was $\sim 2$ in fasted

TABLE I

In Vitro Rates of Lipolysis and Esterification in Epididymal Fat Pads of Fed or Fasted Rats Exposed to LVS S. pneumoniae

\begin{tabular}{lcccccc}
\hline \multicolumn{1}{c}{ Treatment } & $\begin{array}{c}\text { Number } \\
\text { of pairs }\end{array}$ & Weight & $\begin{array}{c}\text { Glycerol } \\
\text { production }\end{array}$ & $\begin{array}{c}\text { FFA } \\
\text { production }\end{array}$ & FFA esterification \\
\hline & & $g$ & $\mu$ mol/g/h & $\mu e q / g / h$ & $\mu e q / g / h$ & $\%$ \\
$\begin{array}{l}\text { Fed } \\
\text { Fasted }\end{array}$ & 15 & $2.95 \pm 0.21$ & $2.21 \pm 0.26$ & $0.29 \pm 0.02$ & $6.07 \pm 0.77$ & $95.3 \pm 0.4$ \\
$\quad \begin{array}{l}\text { Heat-killed } \\
\quad 4 \mathrm{~h}\end{array}$ & 15 & $2.80 \pm 0.24$ & $3.28 \pm 0.15$ & $1.69 \pm 0.22$ & $8.46 \pm 0.39$ & $81.8 \pm 1.9$ \\
$\quad \begin{array}{l}48 \mathrm{~h} \\
\text { Infected }\end{array}$ & 10 & $1.79 \pm 0.19$ & $3.82 \pm 0.12$ & $2.79 \pm 0.27$ & $8.67 \pm 0.41$ & $75.5 \pm 2.4$ \\
$\quad 24 \mathrm{~h}$ & 9 & $2.68 \pm 0.25$ & $3.09 \pm 0.15$ & $2.18 \pm 0.23$ & $7.10 \pm 0.41$ & $76.4 \pm 2.4$ \\
$\quad 48 \mathrm{~h}$ & 11 & $1.95 \pm 0.20$ & $3.24 \pm 0.16$ & $2.19 \pm 0.20$ & $7.54 \pm 0.51$ & $77.5 \pm 2.5$ \\
\hline
\end{tabular}

Data are presented in mean $\pm \mathrm{SE}$ of six rats. 
TABLE II

Effect of Fasting and S. pneumoniae Infection on In Vivo Rate of Oxidation of Prelabeled Body Fat

\begin{tabular}{lcc}
\hline \multicolumn{1}{c}{ Treatment } & $\begin{array}{c}\text { Rate of }{ }^{14} \mathrm{CO}_{2} \\
\text { production }\end{array}$ & $\begin{array}{c}\text { Percentage of total body } \\
{ }^{14} \mathrm{C} \text { loss per day }\end{array}$ \\
\hline & $d p m / d \times 10^{-5}$ & $\% / d$ \\
Fed & $1.75 \pm 0.11$ & $6.68 \pm 0.39$ \\
Fasted & & \\
Heat-killed & & \\
$24 \mathrm{~h}$ & $2.42 \pm 0.29$ & $9.26 \pm 1.11$ \\
$48 \mathrm{~h}$ & $3.28 \pm 0.20$ & $14.94 \pm 1.35$ \\
Infected & & \\
$24 \mathrm{~h}$ & $2.28 \pm 0.13$ & $9.50 \pm 0.96$ \\
$48 \mathrm{~h}$ & $2.76 \pm 0.26$ & $13.03 \pm 1.67$ \\
\hline
\end{tabular}

Data are mean $\pm \mathrm{SE}$ of six rats.

controls and was not significantly different in the infected group at 24 and $48 \mathrm{~h}$.

Effect of infection on hepatic ketogenesis and fatty acid metabolism in vivo and by the perfused liver. After an intravenous lipid load, triglyceride accumulation and disappearance was significantly faster in rats $24 \mathrm{~h}$ after inoculation with $S$. pneumoniae compared to fasted controls. The accumulation of FFA in plasma was similar in both groups, but the rate of disappearance was significantly faster in infected rats than in fasted controls. Despite the more rapid disappearance of plasma triglycerides and FFA, accumulation of plasma $\beta$-hydroxybutyrate was significantly less in the fastedinfected group than in fasted controls.

In the data presented in Table IV, ketogenesis is expressed as micromoles of ketones ( $\beta$-hydroxybutyrate plus acetoacetate) produced per minute per gram liver. When the livers were perfused with the Krebs-Ringer bicarbonate plus $3 \%$ albumin and no added fatty acids, the rates of ketogenesis were very low and not significantly different between fed, fasted, or fasted-infected group (Table IV). The addition of

TABLE III

Effect of S. pneumoniae Infection on Plasma Albumin and FFA Concentrations

\begin{tabular}{lccc}
\hline Treatment & Albumin & FFA & $\frac{\text { Fatty acid }}{\text { Albumin }}$ \\
\hline & g/dl & meq/liter & molar ratio \\
Heat-killed & & & \\
$24 \mathrm{~h}$ & $2.40 \pm 0.07$ & $740 \pm 44$ & $2.07 \pm 0.12$ \\
$48 \mathrm{~h}$ & $2.22 \pm 0.06$ & $622 \pm 31$ & $1.88 \pm 0.09$ \\
$\begin{array}{l}\text { Infected } \\
24 \mathrm{~h}\end{array}$ & $2.09 \pm 0.07$ & $581 \pm 41$ & $2.13 \pm 0.21$ \\
$48 \mathrm{~h}$ & $0.93 \pm 0.11^{*}$ & $140 \pm 16^{*}$ & $2.33 \pm 0.27$ \\
\hline
\end{tabular}

Data are mean $\pm \mathrm{SE}$ of eight rats.

${ }^{*} P \leq 0.01$ vs. 48 -h heat-killed.
TABLE IV

Rate of Ketone Production from Oleic or Octanoic Acid by Perfused Livers from Fed or Fasted Rats Exposed to LVS S. pneumoniae or F. tularensis

\begin{tabular}{|c|c|c|c|}
\hline \multirow[b]{2}{*}{ Treatment } & \multicolumn{3}{|c|}{ Ketogenesis (No. of livers) } \\
\hline & $\begin{array}{l}\text { Krebs-Ringer } \\
\text { bicarbonate } \\
\text { + albumin }\end{array}$ & $\begin{array}{l}\text { Krebs-Ringer } \\
\text { bicarbonate } \\
\text { + albumin } \\
\text { + oleic acid* }\end{array}$ & $\begin{array}{l}\text { Krebs-Ringer } \\
\text { bicarbonate } \\
\text { + albumin } \\
\text { + octanoic acid* }\end{array}$ \\
\hline & \multicolumn{3}{|c|}{ umollmin/g liver } \\
\hline Fed & $\begin{array}{c}0.14 \pm 0.02 \\
(6)\end{array}$ & $\begin{array}{c}0.24 \pm 0.03 \\
(10)\end{array}$ & $\begin{array}{c}0.31 \pm 0.06 \\
(6)\end{array}$ \\
\hline \multicolumn{4}{|l|}{$\begin{array}{l}\text { Fasted } \\
\text { Heat-killed } \\
\quad \text { S. pneu- } \\
\text { moniae }\end{array}$} \\
\hline $24 \mathrm{~h}$ & - & $\begin{array}{c}0.78 \pm 0.08 \\
(6)\end{array}$ & $\begin{array}{c}0.49 \pm 0.04 \\
(5)\end{array}$ \\
\hline $48 \mathrm{~h}$ & $\begin{array}{c}0.21 \pm 0.11 \\
(5)\end{array}$ & $\begin{array}{c}0.79 \pm 0.04 \\
(11)\end{array}$ & $\begin{array}{c}0.65 \pm 0.03 \\
(17)\end{array}$ \\
\hline \multicolumn{4}{|c|}{$\begin{array}{c}\text { Live } S . \text { pneu- } \\
\text { moniae }\end{array}$} \\
\hline $24 \mathrm{~h}$ & - & $\begin{array}{c}0.60 \pm 0.03 \\
(5)\end{array}$ & $\begin{array}{c}0.48 \pm 0.07 \\
(3)\end{array}$ \\
\hline $48 \mathrm{~h}$ & $\begin{array}{c}0.18 \pm 0.02 \\
(5)\end{array}$ & $\begin{array}{c}0.40 \pm 0.03 \ddagger \\
(10)\end{array}$ & $\begin{array}{c}0.58 \pm 0.03 \\
(13)\end{array}$ \\
\hline \multicolumn{4}{|l|}{$\begin{array}{l}\text { Heat-killed } \\
\text { LVS }\end{array}$} \\
\hline $24 \mathrm{~h}$ & - & $\begin{array}{c}0.73 \pm 0.07 \\
(7)\end{array}$ & $\begin{array}{c}0.62 \pm 0.04 \\
(7)\end{array}$ \\
\hline $48 \mathrm{~h}$ & - & $\begin{array}{c}0.67 \pm 0.03 \\
(7)\end{array}$ & $\begin{array}{c}0.65 \pm 0.08 \\
(6)\end{array}$ \\
\hline \multicolumn{4}{|l|}{ LVS } \\
\hline $24 \mathrm{~h}$ & - & $\begin{array}{c}0.52 \pm 0.07 \ddagger \\
(7)\end{array}$ & $\begin{array}{c}0.53 \pm 0.06 \\
(7)\end{array}$ \\
\hline $48 \mathrm{~h}$ & - & $\begin{array}{c}0.30 \pm 0.03 \sharp \S \\
(7)\end{array}$ & $\begin{array}{c}0.40 \pm 0.02 \ddagger \S \\
(6)\end{array}$ \\
\hline
\end{tabular}

Data are mean $\pm \mathrm{SE}$.

* Given as $2.5 \mathrm{ml}$ bolus and $6 \mathrm{ml}$ infusion of $20 \mathrm{mM}$ fatty acid solution.

$\ddagger P \leq 0.01$ vs. 48 -h, heat-killed $S$. pneumoniae.

$\S P \leq 0.01$ vs. 48 -h, heat-killed LVS.

oleic acid to the perfusate resulted in a doubling of the rate of ketogenesis in the livers of fed rats and a fourfold increase in livers from rats fasted for 24 or $48 \mathrm{~h}$. The rate of ketogenesis from oleic acid was significantly reduced in livers of fasted rats $48 \mathrm{~h}$ after inoculation of $S$. pneumoniae or LVS compared to fasted controls given the heat-killed organisms (Table IV). When the livers were perfused with octanoic 
TABLE V

Metabolism of $\left[1-{ }^{14} \mathrm{C}\right]$ Oleic Acid by Perfused Livers from

Fasted Rats 48 h after Inoculation with LVS

S. pneumoniae

\begin{tabular}{lcccc}
\hline \multicolumn{1}{c}{ Treatment } & $\begin{array}{c}\text { Oleic } \\
\text { acid } \\
\text { used }\end{array}$ & Ketones & \multicolumn{1}{c}{$\mathrm{CO}_{2}$} & $\begin{array}{c}\text { Liver } \\
\text { lipids }\end{array}$ \\
\hline & & \multicolumn{4}{c}{$\mu$ mol/100 g liver } \\
Heat-killed & $38.2 \pm 0.5$ & $26.7 \pm 1.5$ & $1.4 \pm 0.2$ & $8.5 \pm 0.6$ \\
Infected & $37.2 \pm 1.4$ & $13.3 \pm 1.9^{*}$ & $1.1 \pm 0.1$ & $21.8 \pm 0.5^{*}$ \\
\hline
\end{tabular}

Data are $\pm \mathrm{SE}$ of six livers.

${ }^{*} P \leq 0.01$ vs. heat-killed.

acid, the rates of ketogenesis were slightly higher in the fed group and lower in the fasted groups compared to livers perfused with oleic acid. No significant difference was observed in the rate of ketogenesis from octanoic acid between livers from fasted controls or fasted rats infected with $S$. pneumoniae. A slight decrease in rates of hepatic ketogenesis was observed $48 \mathrm{~h}$ after LVS, as compared to fasted controls.

When $\left[{ }^{14} \mathrm{C}\right]$ oleic acid was added to the perfusate, the rate of hepatic usage of the label and ${ }^{14} \mathrm{CO}_{2}$ production was similar in livers from fasted rats studied $48 \mathrm{~h}$ after inoculation of the heat-killed or live S. pneumoniae (Table V). In contrast, incorporation of label into ketones was significantly reduced, whereas the formation of labeled lipids was significantly increased in the livers of fasted-infected rats compared to the fasted controls (Table V). Livers from fasted rats had a reduced weight and lipid content compared to those of the fed group (Table VI). Livers from fasted-infected rats were increased in both weight and lipid content as compared to fasted controls. Livers from the fasted rats $48 \mathrm{~h}$ after inoculation with $S$. pneumoniae incorporated significantly more of either labeled octanoic or oleic acid into the lipid fraction than livers from rats studied at $24 \mathrm{~h}$ or fasted controls (Table VI). In all groups the rate of incorporation of labeled octanoic acid into total lipid was significantly less than when $\left[{ }^{14} \mathrm{C}\right]$ oleic acid was perfused.

When compared to fasted controls, the liver from rats $48 \mathrm{~h}$ after inoculation with $S$. pneumoniae contained slightly more free carnitine, and a significantly increased acid soluble acylcarnitine (short chain), whereas no difference was observed in acid insoluble acylcarnitine (long chain) content (Table VII). When hepatic malonyl-CoA concentration was determined by the procedure of McGarry et al. (31), significantly $(P<0.01)$ lower values were obtained in fasted rats as compared to fed, but no difference was observed between infected and heat-killed controls (Table VII). Similar results were obtained when hepatic malonylCoA was measured by the technique of Guynn et al. (32). Hepatic mitochondria isolated from fed, fasted or S. pneumoniae-infected rats showed similar rates of state three and state four respiration, respiratory control index, and ADP:O ratio $(6,17,34)$. No significant differences were observed in the ability of isolated mitochondria to convert fatty acids to ketones in livers from fed, fasted or infected rats (Table VII).

In vivo rate of usage of ketone by infected rats. After an intravenous injection of $\beta-\left[{ }^{14} \mathrm{C}\right]$ hydroxybutyrate, the rate of labeled $\mathrm{CO}_{2}$ production was similar in fasted rats inoculated 24 or $40 \mathrm{~h}$ previously with either heatkilled or live organisms. In contrast, the rate of ${ }^{14} \mathrm{CO}_{2}$

TABLE VI

Effect of Fasting and S. pneumoniae Infection on Liver Weight, Lipid Content, and Incorporation of $\left[{ }^{14} \mathrm{C}\right] \mathrm{Octanoic}$ or Oleic Acid into Liver Lipid during In Vitro Perfusion Studies

\begin{tabular}{|c|c|c|c|c|}
\hline \multirow[b]{2}{*}{ Treatment } & \multirow{2}{*}{$\begin{array}{l}\text { Liver } \\
\text { wt }\end{array}$} & \multicolumn{3}{|c|}{ Liver lipid } \\
\hline & & Weight & {$\left[{ }^{14} \mathrm{C}\right]$ Octanoic } & {$\left[{ }^{14} \mathrm{C}\right]$ Oleic } \\
\hline & g & mg/liver & \multicolumn{2}{|c|}{ dpm/total liver lipid $\times 10^{6}$} \\
\hline $\begin{array}{l}\text { Fed } \\
\text { Fasted }\end{array}$ & $8.16 \pm 0.21$ & $552 \pm 29$ & $1.33 \pm 0.17$ & $5.84 \pm 0.21$ \\
\hline $\begin{array}{l}\text { Fasted } \\
\quad \text { Heat-killed }\end{array}$ & & & & \\
\hline $24 \mathrm{~h}$ & $6.52 \pm 0.11$ & $326 \pm 26$ & $0.35 \pm 0.02$ & $2.71 \pm 0.20$ \\
\hline $48 \mathrm{~h}$ & $6.20 \pm 0.19$ & $300 \pm 13$ & $0.24 \pm 0.03$ & $2.34 \pm 0.17$ \\
\hline \multicolumn{5}{|l|}{ Infected } \\
\hline $24 \mathrm{~h}$ & $7.13 \pm 0.20^{*}$ & $374 \pm 20$ & $0.68 \pm 0.07^{*}$ & $3.62 \pm 0.17^{*}$ \\
\hline $48 \mathrm{~h}$ & $7.89 \pm 0.15 \ddagger$ & $464 \pm 21 t$ & $1.30 \pm 0.12 \ddagger$ & $5.27 \pm 0.14 \ddagger$ \\
\hline
\end{tabular}

Data are $\pm \mathrm{SE}$ of six rats.

${ }^{*} P \leq 0.01$ vs. $24-\mathrm{h}$, fasted heat-killed.

† $P \leq 0.01$ vs. 48 -h, fasted heat-killed. 
TABLE VII

Effect of Fasting and S. pneumoniae Infection on Hepatic Carnitine and Malonyl-CoA Content and Rate of Ketone Production by Liver Mitochondria

\begin{tabular}{|c|c|c|c|c|c|c|c|}
\hline Treatment & $\begin{array}{c}\begin{array}{c}\text { Liver } \\
\text { wt }\end{array} \\
g\end{array}$ & \multicolumn{3}{|c|}{ Carnitine } & & & $\begin{array}{c}\begin{array}{c}\text { Mitochondrial FFA to } \\
\text { ketones }\end{array} \\
\text { nmol ketone/min/mg } P\end{array}$ \\
\hline Fed & $9.2 \pm 0.9$ & $1,274 \pm 120$ & $541 \pm 108$ & $299 \pm 36$ & $13.54 \pm 3.10$ & $122.2 \pm 24.4$ & $2.3 \pm 0.2$ \\
\hline \multicolumn{8}{|l|}{ Fasted } \\
\hline \multicolumn{8}{|l|}{ Heat-killed } \\
\hline \multicolumn{8}{|l|}{ Infected } \\
\hline $24 \mathrm{~h}$ & $6.5 \pm 0.4$ & $1,311 \pm 119$ & $323 \pm 60$ & $295 \pm 19$ & $3.29 \pm 0.83$ & $21.4 \pm 5.2$ & $3.9 \pm 0.6$ \\
\hline $48 \mathrm{~h}$ & $7.0 \pm 0.3^{*}$ & $1,582 \pm 142$ & $902 \pm 106^{*}$ & $383 \pm 43$ & $3.25 \pm 0.65$ & $27.6 \pm 5.4$ & $3.6 \pm 0.8$ \\
\hline
\end{tabular}

Data are $\pm \mathrm{SE}$ of six rats.

${ }^{*} P \leq 0.01$ vs. 48 -h fasted, heat-killed controls.

production was significantly decreased in fasted-infected rats $48 \mathrm{~h}$ after inoculation of $S$. pneumoniae in comparison to fasted controls. Also, after the administration of $\left[{ }^{14} \mathrm{C}\right]$ acetoacetate, rates of labeled $\mathrm{CO}_{2}$ production were similar in all rats at $24 \mathrm{~h}$.

\section{DISCUSSION}

As reported by Vaughan (20), fasting led to an increased glycerol production and a decrease in the percentage of FFA that are esterified to triglycerides. When an S. pneumoniae infection was superimposed on fasting, it had no significant effect on the rates of either lipolysis or esterification in isolated epididymal fat pads. To help validate this conclusion, an in vivo model was developed in which total body fat was prelabeled with ${ }^{14} \mathrm{C}$ and the rates of labeled $\mathrm{CO}_{2}$ production were measured during fasting alone or with a superimposed $S$. pneumoniae infection. Fasting for 24 or $48 \mathrm{~h}$ significantly increased the rate of ${ }^{14} \mathrm{CO}_{2}$ production from labeled body lipids as compared to values obtained in fed rats; however, infection plus fasting did not significantly alter this effect.

Thus, from both in vivo and in vitro studies of depot fat, it may be concluded that the inhibition of calorierestricted ketonemia during pneumococcal sepsis in rats is not the result of altered rates of lipolysis or esterification. However, despite the elevated energy requirement associated with fever $(2,4)$, fatty acid mobilization did not increase in the infected rat, which could explain why epididymal fat did not decrease more than was observed in fasted controls.

In general, plasma FFA concentrations are decreased during sepsis in man and experimental animals $(5,6$, $8,16)$. This decrease can be the result of an increased rate of usage, a decrease in the concentration of the FFA transport protein (albumin), and/or depression in the rates of release of fatty acids from adipose tissue.
Both plasma albumin and FFA concentrations were markedly reduced during pneumococcal sepsis in these rats, but the molar fatty acid:albumin ratio was very similar to that observed in fasted controls. Thus, decreased plasma FFA content was correlated with the depression in plasma albumin concentration in fastedinfected rats.

An important regulator of this mechanism is the concentration of unbound free fatty acid that is in equilibrium with the albumin-bound fatty acids at the site of transport into the cell. Because the affinity of binding of the fatty acid to albumin decreases with increased fatty acid saturation, the unchanged fatty acid:albumin ratio in the infected rat should favor transport into liver at a rate similar to that found in a fasted rat. This possibility can only be tested by measurement of arterial-venous differences across the liver of the infected host.

To overcome the possible effects of fatty acid supply, in vivo studies on the effect of infection on hepatic rates of ketogenesis were carried out with excess exogenous source of fatty acids. When an intravenous lipid load was given to a rat during pneumoncoccal sepsis, plasma triglyceride and FFA disappearance was faster than that observed in fasted controls. Despite an elevated rate of breakdown of triglycerides and usage of FFA, a slower accumulation of plasma $\beta$-hydroxybutyrate was observed in the septic rat as compared to its fasted controls. Thus, it may be concluded that the fatty acids from the lipid load are being deposited in either lipid or adipose tissue. This conclusion was supported by the progressive increase in lipid content and rate of incorporation of labeled oleic acid in the livers from fasted-infected rats compared to controls. As increase in triglyceride synthesis could help to explain the fatty metamorphosis that has been observed in hepatocytes during sepsis (35). 
To evaluate further the effects of infection on rates of hepatic ketogenesis studies were carried out with isolated livers perfused with long- and medium-chain fatty acids. When oleic acid (a long-chain FFA) was used as a substrate to study regulation of ketogenesis, livers from fasted rats had a threefold enhancement in the rate of ketone production compared to those of fed rats. This effect of fasting is very similar to the observations reported by McCarry and Foster (29) and indicates that the procedure used in these studies was an adequate model for studying the regulation of ketogenesis in the isolated perfused liver system. The livers from fasted rats $48 \mathrm{~h}$ after inoculation of $S$. pneumoniae or 24 or $48 \mathrm{~h}$ after $F$. tularensis had much lower rates of ketogenesis compared to fasted noninfected controls. These observations clearly indicated that both of these infections depressed the ketogenic capacity of the liver when the rat was subjected to complete caloric restriction. In livers from rats infected with pneumococci, the reduced rate of ketogenesis was not related to an altered rate of uptake of oleic acid by the perfused livers.

When octanoic acid (a medium-chain FFA) was utilized as a substrate to study regulation of ketogenesis, only very minimal enhancement of ketone production was observed in livers of fasted rats compared to those in the fed group. Further, the $S$. pneumoniae infection had little effect on the rate of ketogenesis when isolated livers were perfused with this medium-chain fatty acid. The small decrease in the later stages of the $F$.tularensis infection may be related to a reduced uptake of fatty acid by liver. Data from these studies support the conclusions of McGarry and Foster $(13,28)$ that the major regulatory mechanisms for the oxidation of long-chain fatty acids is not operative when mediumchain fatty acids serve as a ketogenic substrate.

McGarry and Foster $(13,28)$ have presented evidence to indicate that the increased ketogenic capacity of livers from starved or diabetic rats appears to result mainly from an increased ability of the liver to transport activated fatty acids from cytosol to the mitochondria. The transport of long-chain fatty acids into mitochondria is catalyzed by "carnitine acyltransferase" (carnitine palmitoyltransferase, EC 2.3.1.21), which is an enzyme system comprised of carnitine acyltransferase I and II (36). Since the infection-related decrease in ketogenic capacity of liver was only observed when long-chain fatty acids were used as substrate, it may be hypothesized that the infectious process exerts some inhibitory effects on a carnitine acyltransferase system of the liver.

From the data on ${ }^{14} \mathrm{CO}_{2}$ production from oleic acid and the oxygen consumed by isolated mitochondria, it may be concluded that Krebs cycle activity was not significantly altered in the liver during pneumococcal sepsis. Because ketogenesis was not altered in isolated mitochondria, it can be concluded that carnitine acyltransferase was not rate-limiting in the liver of infected rats. The apparent lack of correlation in the rate of ketogenesis in perfused liver with that in homogenates or isolated mitochondria has been observed by other investigators $(33,34)$ and has been related to a possible loss of cytoplasmic regulatory factors that are disturbed by homogenization and isolation of the mitochondria. One such factor, hepatic carnitine content, has been suggested by McGarry and co-workers (37) as a possible regulator of ketogenesis, but the increases in hepatic carnitine in the infected rat suggest that this was not responsible for the reduced ketogenic capacity of these livers. Preliminary observations have suggested that the livers of infected rats have a reduced concentration of total acid-soluble CoA and acyl-CoA (38). The intra- and extramitochondrial distribution of the reduced CoA content of the liver of infected rats could be related to their decreased ketogenic capacity.

Livers from fasted-infected rats also incorporated labeled carbon from octanoic acid into liver lipids at a faster rate than did their fasted controls. Because octanoate is not known to be used directly for triglyceride synthesis $(13,36)$, an increased amount of the acetyl-CoA, from $\beta$-oxidation in the mitochondria, was transported to the cytoplasm and subsequently used for the synthesis of C-16 and C-18 fatty acids in livers from infected rats. One of the intermediates in fatty synthesis is malonyl-CoA, which could play a role in regulation of the rate of hepatic ketogenesis in mealfed rats (33). Because no significant differences were observed in the hepatic concentration of malonylCoA in infected rats, this intermediate is probably not responsible for the reduced hepatic ketogenesis during sepsis.

From these studies, it may be concluded that the general failure of ketonemic adaptation to starvation to occur during the caloric deprivation associated with severe sepsis is a result of both a reduced ketogenic capacity of the liver and a possibly decreased supply of fatty acids. Further, from the studies with labeled $\beta$-hydroxybutyrate and acetoacetate, it is apparent that the failure of ketonemia to develop during caloric restriction in the infected host is probably not the result of the increased usage of ketones by peripheral tissues. Because of the marked decrease in total body ketone pool and the inability to increase lipolysis during fever, the septic host increases the breakdown of body protein and usage of amino acids as a source of energy, with a resulting elevation of gluconeogenesis, ureagenesis, and ammoniagenesis $(7,8)$.

\section{REFERENCES}

1. Cahill, G. F., Jr., T. T. Aoki, and E. B. Marliss. 1971. Insulin and muscle protein. Handb. Physiol. 1(Sect. 7, Endocrinology): 563-577. 
2. Flatt, J-P., and G. L. Blackburn. 1974. The metabolic fuel regulatory system: implications for protein-sparing therapies during caloric deprivation and disease. Am.J. Clin. Nutr. 27: 175-187.

3. Border, J. R., R. Chenier, R. H. McManamy, J. LaDuca, R. Seibel, R. Birkhahn, and L. Yu. 1976. Multiple systems organ failure: muscle fuel deficit with visceral protein malnutrition. Surg. Clin. N. Am. 56: 1147-1167.

4. Wannemacher, R. W., Jr., M. V. Kaminski, Jr., H. A. Neufeld, R. E. Dinterman, K. A. Bostian, and C. L. Hadick. 1978. Protein-sparing therapy during pneumococcal sepsis in rhesus monkeys. J. Parenteral Enteral Nutr. 2: $507-518$.

5. Ryan, N. T., G. L. Blackburn, and G. H. A. Clowes, Jr. 1974. Differential tissue sensitivity to elevated endogenous insulin levels during experimental peritonitis in rats. Metab. Clin. Exp. 23: 1031-1089.

6. Neufeld, H. A., J. A. Pace, and F. E. White. 1976. The effect of bacterial infections on ketone concentrations in rat liver and blood and on free fatty acid concentrations in rat blood. Metab. Clin. Exp. 25: 877-884.

7. Wannemacher, R. W., Jr. 1977. Key role of various individual amino acids in host response to infection. Am.J. Clin. Nutr. 30: 1269-1280.

8. Blackburn, G. L. 1977. Lipid metabolism in infection. Am. J. Clin. Nutr. 30: 1321-1332.

9. Seyffert, W. A., Jr., and L. L. Madison. 1967. Physiological effects of metabolic fuels on carbohydrate metabolism. I. Acute effect of elevation of plasma free fatty acids on hepatic glucose output, peripheral glucose utilization, serum insulin, and plasma glucagon levels. Diabetes. 16: $765-776$.

10. Foster, D. W. 1967. Studies in the ketosis of fasting. J. Clin. Invest. 46: 1283-1296.

11. Crespin, S. R., W. B. Greenough, III, and D. Steinberg. 1969. Stimulation of insulin secretion by infusion of free fatty acids. J. Clin. Invest. 48: 1934-1943.

12. Williamson, D. H., D. Veloso, E. V. Ellington, and H. A. Krebs. 1969. Changes in the concentrations of hepatic metabolites on administration of dihydroxyacetone or glycerol to standard rats and their relationship to the control of ketogenesis. Biochem. J. 114: 575-584.

13. McGarry, J. D., and D. W. Foster. 1971. The regulation of ketogenesis from octanoic acid. The role of the tricarboxylic acid cycle and fatty acid synthesis. J. Biol. Chem. 246: 1149-1159.

14. Bates, M. W., H. A. Krebs, and D. H. Williamson. 1968. Turnover rates of ketone bodies in normal, starved and alloxan-diabetic rats. Biochem. J. 110: 655-661.

15. McGarry, J. D., M. J. Guest, and D. W. Foster. 1970. Ketone body metabolism in the ketosis of starvation and alloxan diabetes. J. Biol. Chem. 245: 4382-4390.

16. Beisel, W. R., and R. H. Fiser, Jr. 1970. Lipid metabolism during infectious illness. Am. J. Clin. Nutr. 23: 10691079.

17. Pace, J. A., F. A. Beall, H. A. Neufeld, and R. W. Wannemacher, Jr. 1977. Alterations in carnitine (Car) acylation states in S. pneumoniae infected (INF) rats. Fed. Proc. 36: 788. (Abstr.)

18. Wannemacher, R. W., Jr., M. C. Powanda, R. S. Pekarek, and W. R. Beisel. 1971. Tissue amino acid flux after exposure of rats to Diplococcus pneumoniae. Infect. Immun. 4: 556-562.

19. Powanda, M. C., R. E. Dinterman, R. W. Wannemacher, Jr., and G. D. Herbrandson. 1974. Distribution and metabolism of phenylalanine and tyrosine during tularaemia in the rat. Biochem. J. 144: 173-176.

20. Vaughan, M. 1962. The production and release of glycerol by adipose tissue incubated in vitro. J. Biol. Chem. 237: 3354-3358.
21. Rush, R. L., L. Leon, and J. Turrell. 1970. Automated simultaneous cholesterol and triglyceride determination on the AutoAnalyzer II instrument. In Advances in Automated Analysis. Technicon International Congress. 1: 503-507.

22. Dalton, C., and C. Kowalski. 1967. Automated colorimetric determination of free fatty acids in biological fluids. Clin. Chem. 13: 744-751.

23. Allison, J. B., R. W. Wannemacher, Jr., W. L. Banks, Jr., and $\mathrm{W}$. H. Wunner. 1964. The magnitude and significance of the protein reserves in rats fed at various levels of nitrogen. J. Nutr. 84: 383-388.

24. Wannemacher, R. W., Jr., A. S. Klainer, R. E. Dinterman, and W. R. Beisel. 1976. The significance and mechanism of an increased serum phenylalanine-tyrosine ratio during infection. Am. J. Clin. Nutr. 29: 997-1006.

25. Bostian, K. A., B. S. Blackburn, R. W. Wannemacher, Jr., V. G. McGann, W. R. Beisel, and H. L. Dupont. 1976. Sequential changes in the concentration of specific serum proteins during typhoid fever infection in man. J. Lab. Clin. Med. 87: 577-585.

26. Miller, L. L. 1961. Some direct actions of insulin, glucagon, and hydrocortisone on the isolated perfused rat liver. Recent Prog. Horm. Res. 17: 539-568.

27. Zenser, T. V., F. R. DeRubertis, and R. T. Curnow. 1974. Effects of prostaglandins on hepatic adenylate cyclase activity and cyclic adenosine $3^{\prime}, 5^{\prime}$-monophosphate content. Endocrinology. 94: 1404-1410.

28. McGarry, J. D., and D. W. Foster. 1971. The regulation of ketogenesis from oleic acid and the influence of antiketogenic agents. J. Biol. Chem. 246: 6247-6253.

29. Zivin, J. A., and J. F. Snarr. 1973. An automated colorimetric method for the measurement of 3-hydroxybutyrate concentration. Anal. Biochem. 52: 456-461.

30. Pace, J. A., R. W. Wannemacher, Jr., and H. A. Neufeld. 1978. Improved radiochemical assay for carnitine and its derivatives in plasma and tissue extracts. Clin. Chem. 24: 32-35.

31. McGarry, J. D., M. J. Stark, and D. W. Foster. 1978. Hepatic malonyl-CoA levels of fed, fasted and diabetic rats as measured using a simple radioisotope assay. J. Biol. Chem. 253: 8291-8293.

32. Guynn, R. W., D. Veloso, and R. L. Veech. 1972. The concentration of malonyl-coenzyme $A$ and the control of fatty acid synthesis in vitro. J. Biol. Chem. 247: 73257331 .

33. McGarry, J. D., G. P. Mannaerts, and D. W. Foster. 1977. A possible role for malonyl-CoA in the regulation of hepatic fatty acid oxidation and ketogenesis. J. Clin. Invest. 60: 265-270.

34. DiMarco, J. P., and C. Hoppel. 1975. Hepatic mitochondrial function in ketogenic states. Diabetes, starvation, and after growth hormone administration. J. Clin. Invest. 55: 1237-1244.

35. von Brand, T., and T. I. Mercado. 1958. Quantitative and histochemical studies on liver lipids of rats infected with Plasmodium berghei. Am. J. Trop. Med. Hyg. 67: 311320.

36. Fritz, I. B. 1961. Factors influencing the rates of longchain fatty acid oxidation and synthesis in mammalian systems. Physiol. Rev. 41: 52-129.

37. McGarry, J. D., C. Robles-Valdes, and D. W. Foster. 1975. Role of carnitine in hepatic ketogenesis. Proc. Natl. Acad. Sci. U. S. A. 72: 4385-4388.

38. Pace, J. G., F. A. Beall, M. D. Foulke, H. A. Neufeld, and R. W. Wannemacher, Jr. 1978. Regulation of fatty acid utilization in isolated perfused livers from Streptococcus pneumoniae infected rats. Clin. Res. 26: 627A. (Abstr.) 